\title{
Estudo de habitat urbano de mamífero nativo Hydrochoerus hydro- chaeris (Linnaeus, 1766) (capivara) com uso de Sensoriamento Remoto, Curitiba, Paraná, Brasil
}

\author{
Study of urban habitat of native mammal Hydrochoerus hydrochaeris (capybara) with \\ use of Remote Sensing, Curitiba, Paraná, Brazil
}

\author{
Ariádina Maria Reis de Almeida ${ }^{1}$, Mayssa Mascarenhas Grise ${ }^{2}$, Daniela Biondi ${ }^{3}$, \\ Demóstenes Ferreira da Silva Filho ${ }^{4}$ \\ 1,2,3 Universidade Federal do Paraná, Curitiba/PR, Brasil \\ ${ }^{4}$ Universidade de São Paulo, São Paulo - SP - Brasil
}

\begin{abstract}
Resumo
Há diversas formas de estudar a paisagem buscando compreender a relação entre a fauna e, nos últimos anos, o sensoriamento remoto tem demonstrado ser uma boa ferramenta. Tendo em vista a importância desta ferramenta, esta pesquisa teve como intuito analisar a paisagem de três parques urbanos como habitat para a capivara, utilizando imagem de alta resolução. As áreas estudadas foram o parque Tanguá, parque Tingui e parque Barigui, todos pertencentes ao município de Curitiba/PR. Para o desenvolvimento do estudo, a imagem foi classificada e processada em software MultiSpec. Nele foram geradas dez classes, as quais foram agrupadas em quatro elementos paisagísticos relevantes para a ocorrência de Hydrochoerus hydrochaeris em ambiente urbano: água, floresta, gramado e área impermeável. Os resultados indicaram que existem diferenças paisagísticas entre os parques estudados e que todos apresentam características que favorecem a presença das capivaras como, presença de água e de vegetação arbórea e arbustiva. Evidenciou também a importância destes parques como refúgio para a fauna silvestre no município de Curitiba, Paraná.
\end{abstract}

Palavras-chave: Fauna, Parque urbano, Estudo da paisagem.

\begin{abstract}
There are several ways to study the landscape seeking to understand the relationship between wildlife and, in recent years, remote sensing has been a good tool. Given the importance of this tool, this study was meant to examine the landscape of three urban parks as habitat for capybara, using high resolution image. The areas studied were Tanguá park, Tingui park and Barigüi park, all belonging to Curitiba / PR. To develop the study, the image was processed and classified in MultiSpec software. Ten classes were generated, which were grouped into four landscape elements relevant to the occurrence of Hydrochoerus hydrochaeris in urban environment: water, forest, grassland and impervious area. The results indicated that there are differences between the studied landscape parks and all have characteristics that favor the presence of capybara as the presence of water and tree and shrub vegetation. Also highlighted the importance of these parks as a refuge for wildlife in Curitiba, Paraná.
\end{abstract}

Keywords: Fauna, Urban park, Landscape Study. 


\section{Introdução}

A redução e fragmentação dos ambientes naturais influenciam diretamente a fauna terrestre. Com a redução da disponibilidade de habitats, os animais tentam adaptar-se a constante disputa pelos poucos recursos que restaram. Diante disso, muitas espécies estão se tornando extintas localmente, principalmente aquelas mais exigentes quanto ao habitat e recursos. Apenas as espécies mais plásticas toleram e se beneficiam da transformação destas áreas, podendo viver, inclusive, em ambientes urbanizados (FERNANDEZ, 2004; VARGAS et al., 2007). Para os animais, as manchas de vegetação urbana são vitais, pois são nestes ambientes que eles encontram os recursos básicos para a sua sobrevivência.

Sendo assim, as áreas verdes urbanas tornam-se ambientes fundamentais não somente para a garantia da qualidade de vida humana e para o equilíbrio do meio urbano, mas também exercem uma importante função ecológica (DANTAS; SOUZA, 2004; BIONDI; ALTHAUS, 2005; ROPPA, et al., 2007).

Além da presença destas áreas, a forma, o tamanho e a conectividade também são essenciais, pois, muitas vezes estes são fatores limitantes para a sobrevivência de animais em cidades (SPIRN, 1995; RODRIGUES et al., 2002; SILVEIRA, 1999). De maneira geral, a conectividade entre fragmentos se dá por corredores os quais favorecem a manutenção dos processos dos ecossistemas, fundamentais para a garantia da biodiversidade. Estes corredores desempenham a importante função de conectar e manter a heterogeneidade da matriz de hábitats, proporcionando o fluxo gênico entre populações isoladas (HOBBS; HUENNEKE, 1992; SILVEIRA, 1999; MMA, 2006).

Curitiba, uma das cidades brasileiras que se destaca pela presença de numerosas áreas verdes, onde abriga várias espécies da fauna do Brasil. Nela podem ser encontradas muitas espécies de mamíferos, incluindo marsupiais, morcegos (MIRETZKI, 1996; ALMEIDA et al., 2011) e, até mesmo, Lontra longicaudis (Olfers, 1818), uma espécie que se encontra em perigo de extinção (BRESSAN, 2009; MARGARIDO; BRAGA, 2004). Além destas, um grande número de aves faz parte dessa riqueza animal que se beneficia de alimento e abrigos disponíveis nos bosques e nos parques da cidade (STRAUBE et al., 2009).

Hydrochoerus hydrochaeris (Linnaeus, 1766), conhecida popularmente por capivara, é uma das espécies nativas mais tolerantes e, que ao longo do tempo, está se adaptando às transformações ambientais, sendo encontrada, inclusive, em grandes centros urbanos como São Paulo e Curitiba (FERRAZ et al., 2001; VERDADE; FERRAZ, 2006; PEREIRA; ESTON, 2007; ALMEIDA et al., 2013)

A capivara, o maior roedor das Américas, é um mamífero de hábito semiaquático que vivem em áreas úmidas, cuja alimentação é baseada em vegetação terrestre e aquática (MOREIRA; MACDONALD, 1997;
QUINTANA et al., 1998; CREED, 2004; OLIVEIRA; BONVICINO, 2011). É um animal social que forma grupos de tamanho e composição variada, possui um repertório comportamental bastante complexo que é importante na manutenção e sobrevivência da espécie (HERRERA; MACDONALD, 1987; ALHO et al., 1987; BARROS et al., 2011). Apresenta uma forte relação com a água, sendo este o elemento da paisagem determinante para a permanência da espécie em um ambiente (SCHALLER; CRAWSHAW, 1981; MOREIRA; MACDONALD, 1997; ALMEIDA, 2012).

Encontra-se rara ou extinta em muitas regiões onde antes era comum (OLIVEIRA; BONVICINIO, 2011), mas rapidamente prolifera a ponto de se tornar abundante em regiões favoráveis em que seja protegida. Por esta razão, sua população é significativamente maior em ambientes alterados, onde a ausência de predadores naturais e a disponibilidade de recursos naturais favorecem este acontecimento (FERRAZ et al., 2003; FERRAZ et al., 2007; FERRAZ et al., 2009).

Apesar de estar amplamente distribuída na América do Sul e no Brasil, são poucos os estudos sobre a capivara em ambiente sob influência humana ou áreas antropizadas. Neste contexto, a busca de informações sobre a espécie em ambientes urbanos auxiliará na ampliação da compreensão das questões relativas à biologia da espécie.

O Sensoriamento Remoto e as técnicas de processamento digital de imagens são muito utilizados para analisar e diagnosticar aspectos ambientais importantes (GARCIA et al., 2013). São ferramentas de grande importância para biologia da conservação, por meio delas são viabilizados estudos de ecologia da paisagem que analisam a relação fauna $x$ habitats (FIRKOSKI, 1991; MANTOVANI, 2006). A ecologia da paisagem é um ramo da ciência que procura entender a dinâmica entre as comunidades biológicas e a floresta em diferentes estádios de sucessão ecológica e perturbação, permitindo que os processos ecológicos possam ser estudados em diferentes escalas espaciais e temporais (RISSER, 1987; PORTO; MENEGAT 2004).

O uso de imagens de satélite para a classificação da vegetação é uma ferramenta prática e de rápida análise (GARCIA et al., 2013). Diante desta realidade e da carência de estudos sobre capivara nas cidades paranaenses, esta pesquisa teve como objetivo identificar e quantificar, a partir do tratamento digital de imagens de sensoriamento remoto, os elementos da paisagem que compõem o habitat da capivara em três parques públicos do município de Curitiba, capital do estado do Paraná. O conhecimento gerado por este estudo contribuirá para a conservação e manejo deste roedor de grande porte em ambientes urbanos. 


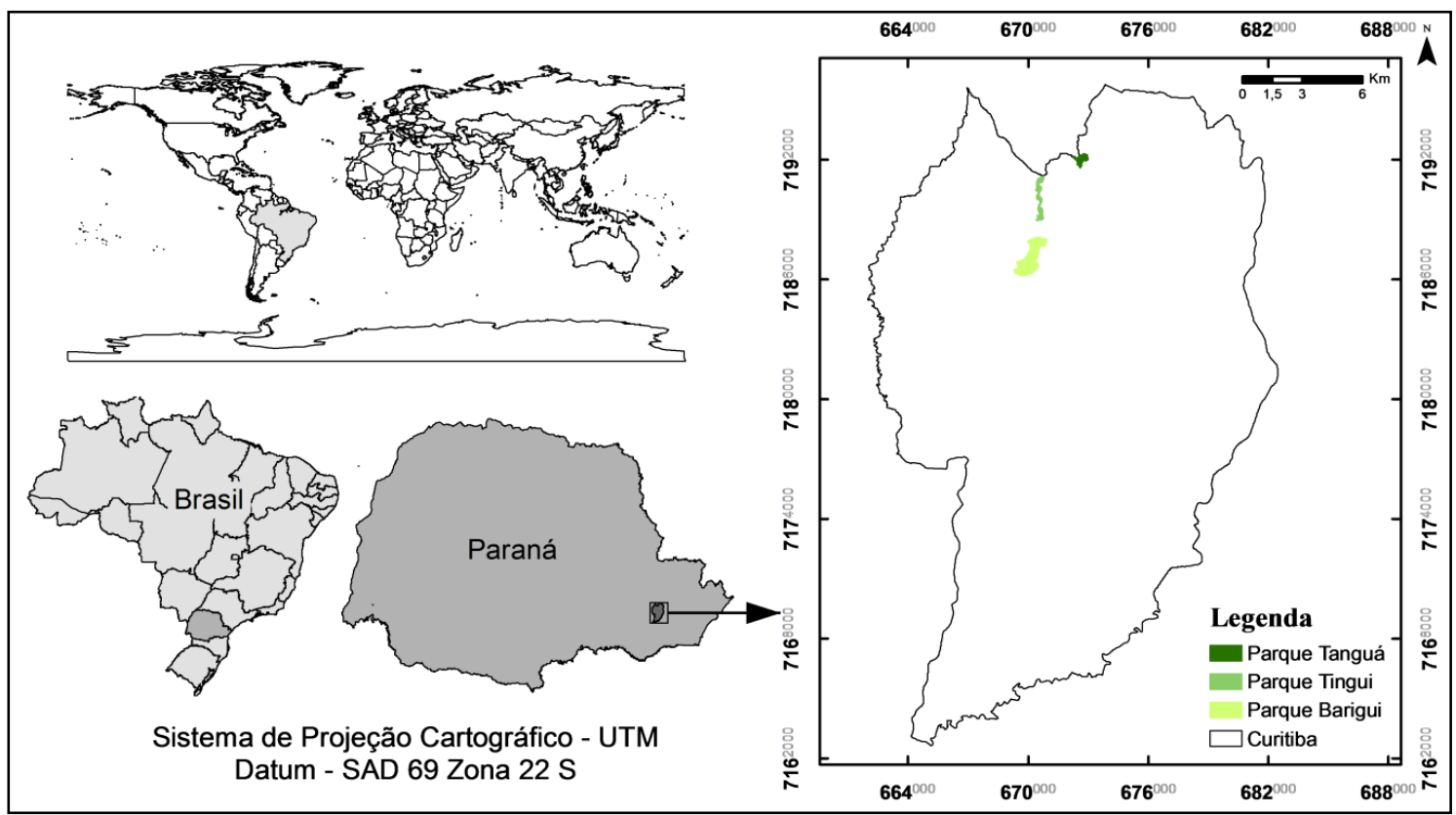

Figura 1. Localização dos parques Tanguá, Tingui e Barigui, Curitiba-PR

\section{Material e métodos}

\subsection{Caracterização da área de estudo}

Esta pesquisa foi desenvolvida no Parque Tanguá $\left(25^{\circ} 22^{\prime} 46^{\prime \prime} \mathrm{S}\right.$ e $\left.49^{\circ} 16^{\prime} 57^{\prime \prime} \mathrm{W}\right)$, parque Tingui $\left(25^{\circ} 23^{\prime} 43^{\prime \prime} \mathrm{S}\right.$ e $\left.49^{\circ} 18^{\prime} 15^{\prime \prime} \mathrm{W}\right)$ e parque Barigui $\left(25^{\circ} 25^{\prime} 12^{\prime \prime} \mathrm{S}\right.$ e $\left.49^{\circ} 18^{\prime} 26^{\prime \prime} \mathrm{W}\right)$, áreas localizadas na região norte de Curitiba-PR (Figura 1). São Unidades de Conservação Municipais classificadas como Parques de Conservação pela lei 9.804 de 2000, a qual criou o sistema de unidades de conservação de Curitiba (PARQUE E PRAÇAS DE CURITIBA, 2013).

Segundo classificação climática de Köppen, Curitiba está situada em região climática do tipo $\mathrm{Cfb}$, com clima temperado (ou subtropical) úmido, sem estação seca, com verões frescos, invernos com geadas frequentes e ocasionais precipitações de neve. Os ventos predominantes são de Leste, com velocidade média anual de $2,1 \mathrm{~m} / \mathrm{s}$. As médias de temperatura são de $20,94^{\circ} \mathrm{C}$ no verão e $13,77^{\circ} \mathrm{C}$ no inverno. A precipitação média anual é de $1.563,30 \mathrm{~mm}$; e a umidade média relativa do ar é de $80,81 \%$ (IPPUC, 2010).

Os três parques estudados são conectados pelo rio Barigui (verificar grafia - há duas formas ao longo do texto), corpo d'água que percorre 45 quilômetros da cidade de Curitiba (IPPUC, 2013). Eles fazem parte do parque Linear do Barigui e foram criados com o intuito de proteger o sistema natural de drenagem do rio, além de preservar as floretas e a fauna associadas a este ecossistema (PMC, 2002).

O parque Tanguá foi inaugurado em 1996 em um antigo conjunto de pedreiras desativadas. Ocupa uma área de 235 mil metros quadrados e está localizado no bairro Pilarzinho, onde é delimitado a nordeste, a leste e a sudoeste por ruas asfaltadas e a oeste pelo Rio Barigui. A área compreende um paredão de pedra (no local onde existia uma pedreira), um lago artificial, um jardim com chafariz, ciclovias, pistas de Cooper e outras infraestruturas necessárias aos visitantes e aos funcionários do parque. Apresenta declividade máxima de $15 \%$, com exceção do paredão de pedra, que possui ângulos de até $90^{\circ}$. Seu entorno é formado por algumas áreas de vegetação arbórea/florestal, por condomínios residenciais horizontais e por habitações que já existiam no bairro antes da criação do parque (PMC, 2002).

O parque Tingui foi criado também em 1996 em área de Floresta Ombrófila Mista Aluvial, onde havia cavas resultantes de extração de areia. Abrange uma área de 380 mil metros quadrados, formando uma estrutura alongada de norte a sul. O rio Barigui, representa o limite leste e sul e ruas asfaltadas os limites norte e oeste. A maior parte do parque é representada por terrenos aluvionares e aterros com declividade de até $5 \%$, porém existe uma faixa contínua de floresta cuja declividade é acima de $10 \%$. Com relação ao entorno, aproximadamente 60\% (ALMEIDA, 2012) é composto por vegetação de chácaras e fazendas, enquanto que os outros $40 \%$ são representados por zona comercial, zona habitacional de alto padrão e de ocupação controlada (PMC, 2009).

O parque Barigui, um dos primeiros parques a serem criados em Curitiba, foi inaugurado em 1972 e possui 1.400 mil metros quadrados de área (IAP, 2012). É um dos maiores e mais representativos remanescentes florestais do Município, com cerca de $50 \%$ de sua área constituída por floresta (ABE et al., 2000). Apresenta declividade predominante de $5 \%$, em áreas de fundo de vale, mas pode chegar a $30 \%$, nas partes florestadas (PMC, 2007).

A paisagem destes três parques é composta pelo rio 
Barigui, lagos, gramados e remanescentes de Floresta Ombrófila Mista distribuídos ao longo de suas áreas. Por serem parques públicos e a recreação/lazer ser uma de suas finalidades, também contempla toda infraestrutura necessária à visitação (playground, churrasqueiras, canchas esportivas, equipamentos para ginástica, trilhas asfaltadas, estacionamentos, e sanitários) (PMC, 2002 e 2007).

Estas áreas verdes, além de representarem relevantes remanescentes florestais urbanos, são importantes como refúgio para a fauna silvestre e urbana. A capivara é um dos mamíferos que se destaca nestas áreas, e já foi registrada sua presença nos parques Tanguá, Tingui e Barigui (ALMEIDA et al., 2013).

\subsection{Base de dados}

Para realização deste estudo foram utilizadas imagens digitais do Satélite GeoEye-1 com resolução espacial de 0,5 m na imagem fusionada, datadas de janeiro de 2010 . Estas imagens foram adquiridas ortorretificadas pelo método da Reamostragem por Interpolação Bilinear.

Foram utilizados os softwares MultiSpec para o processamento e classificação da imagem, e o software Quantum GIS para o pós-processamento da imagem.

\subsection{Procedimentos metodológicos}

A imagem Geoye foi recortada utilizando-se um buffer ao redor da área dos parques amostrados - Tanguá, Tingui e Barigui. A imagem recortada foi classificada pelo método ECHO de Classificação Supervisionada Automática no software MultiSpec. Foram estabelecidas 10 classes de cobertura do solo: água, piscina, telha clara, telha escura, telha cinza, telha cerâmica, asfalto, árvore, relvado e areia, além do fundo de imagem que não foi considerado para a análise (Figura 2). Foram utilizadas amostras de treinamento e de teste, cuja acurácia se deu pela estatística Kappa. Esta apresentou 94,5\% de acerto para as amostras de treinamento e $93,8 \%$ de acerto para as amostras teste, ou seja, se mostrou ótima, segundo a interpretação deste índice por Landis e Koch (1977).

Como o objetivo desta pesquisa foi estudar o habitat de capivara, as classes de cobertura do solo foram agrupadas em função de quatro elementos da paisagem (Água, Floresta, Gramado e Área impermeável) que re-
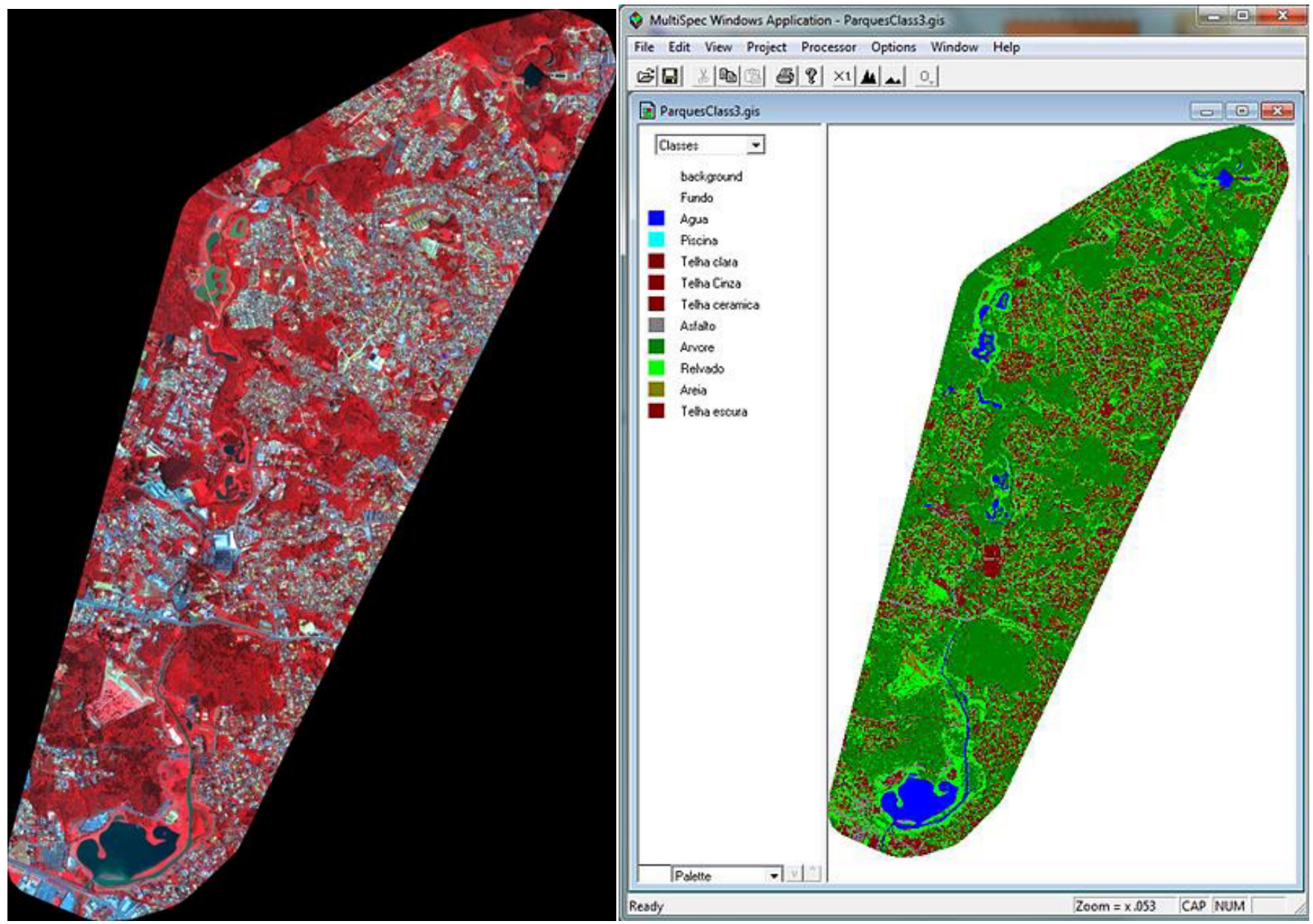

Figura 2. Área dos parques amostrados: (A) buffer, (B) classes geradas no MultiSpec 
Tabela 1. Elementos paisagísticos baseados nas classes geradas pelo MultiSpec.

\begin{tabular}{ll}
\hline Elemento paisagístico & Classe \\
\hline Água & Água e piscina \\
Floresta & Árvore \\
Gramado & Relvado \\
Área impermeável & Asfalto, telha clara, telha escura, telha \\
& cinza, telha de cerâmica e areia. \\
\hline
\end{tabular}

presentam influência sob este animal por ter elementos que fazem parte dos seus processos fisiológicos, reprodutivos e de proteção contra os predadores. Sendo assim, o estudo foi conduzido com base em quatro elementos paisagísticos (Tabela 1).

Para analisar os elementos paisagísticos em cada parque, arquivos shape do limite dos parques (obtidos no site do IPPUC, 2003) foram utilizados para recortar a imagem Raster da figura 1B. Desta forma, foi possível analisar os parques separadamente.

As frequências dos elementos paisagísticos dos três parques foram comparadas como o intuito de saber se existe diferença entre a cobertura do solo destas áreas. Para isso foi utilizado o Teste de Qui-quadrado $(\chi 2)$ a $5 \%$ de significância.

\section{Resultado e discussão}

Os três parques analisados neste estudo apresentam paisagens semelhantes, compostas pelos mesmos elementos paisagísticos, tais como: Água, Floresta, Gramado e Área impermeável (Figura 3). Neste trabalho, o elemento paisagístico Água, representa lagos e rios que se encontram nos parques; a Floresta representa fragmentos de vegetação arbórea e o Gramado, a vegetação rasteira. A ocorrência de capivara em um ambiente se dá pela presença de água, de floresta e de vegetação de cobertura (HERRERA; MACDONALD, 1987; KRAUER, 2009). Neste sentido, a presença destes três elementos nos parques estudados explica a ocorrência dos animais constatada por Almeida et al. (2013) nos parques Tanguá, Tingui e Barigui, entre os anos de 2008 a 2010.

A comparação estatística entre os elementos paisagísticos de cada parque reforçam a ideia exposta anteriormente, pois o teste estatístico indicou não haver diferença entre os parques Tanguá, Tingui e Barigui ( $\chi 2$ $=9,51$ ) (Tabela 2). Este resultado indica que os animais poderiam estabelecer-se em qualquer um dos parques, pois eles oferecem os recursos água, floresta e gramado de forma similar para a exigência mínima da espécie animal estudada.

Como as capivaras se encontram em um ambiente urbanizado, onde existem muitas construções e ruas que recortam as poucas áreas vegetadas da cidade, é de se esperar que as capivaras sofram alguma influência negativa destas áreas impermeabilizadas. As construções exercem pressão no sentido de reduzir a quantidade de ambiente "natural", já às ruas asfaltadas têm um agravante que põem em risco a vida dos animais ao serem atropelados. Estudos comprovam o grande impacto que as ruas e estradas exercem sob a fauna silvestre (BAGATINI, 2006, TURCI; BERNARDE, 2008). No parque Tingui, entre 2008 e 2011 era comum avistar algumas capivaras atravessando a rua que contorna o parque, para chegar à vegetação de área adjacente (Observação

Tabela 2. Área e frequência dos elementos paisagísticos de três parques Municipais de Curitiba/PR

\begin{tabular}{lllllll}
\hline \multirow{2}{*}{$\begin{array}{l}\text { Elemento } \\
\text { paisagístico }\end{array}$} & \multicolumn{2}{c}{ Tanguá } & \multicolumn{2}{c}{ Tingui } & \multicolumn{2}{c}{ Barigui } \\
\cline { 2 - 7 } & Área $\left(\mathbf{m}^{2}\right)$ & $\mathbf{\%}$ & Área $\left(\mathbf{m}^{2}\right)$ & $\%$ & Área $\left(\mathbf{m}^{2}\right)$ & $\%$ \\
\hline Água & $19.839,80$ & 9,1 & $71.803,45$ & $\underline{19,6}$ & $226.372,90$ & 16,8 \\
Floresta & $127.039,89$ & $\underline{58,3}$ & $170.788,56$ & 46,6 & $692.559,70$ & 51,4 \\
Gramado & $41.434,90$ & 19,0 & $100.690,68$ & $\underline{27,4}$ & $280.292,86$ & 20,8 \\
Área impermeável & $29.571,67$ & $\underline{13,6}$ & $23.560,08$ & 6,4 & $147.796,81$ & 11,0 \\
\hline Total & $217.886,26$ & 100,0 & $366.842,76$ & 100,0 & $1.347 .022,27$ & 100,0 \\
\hline
\end{tabular}

* Em destaque (sublinhado) os maiores valores observados em cada elemento paisagístico 


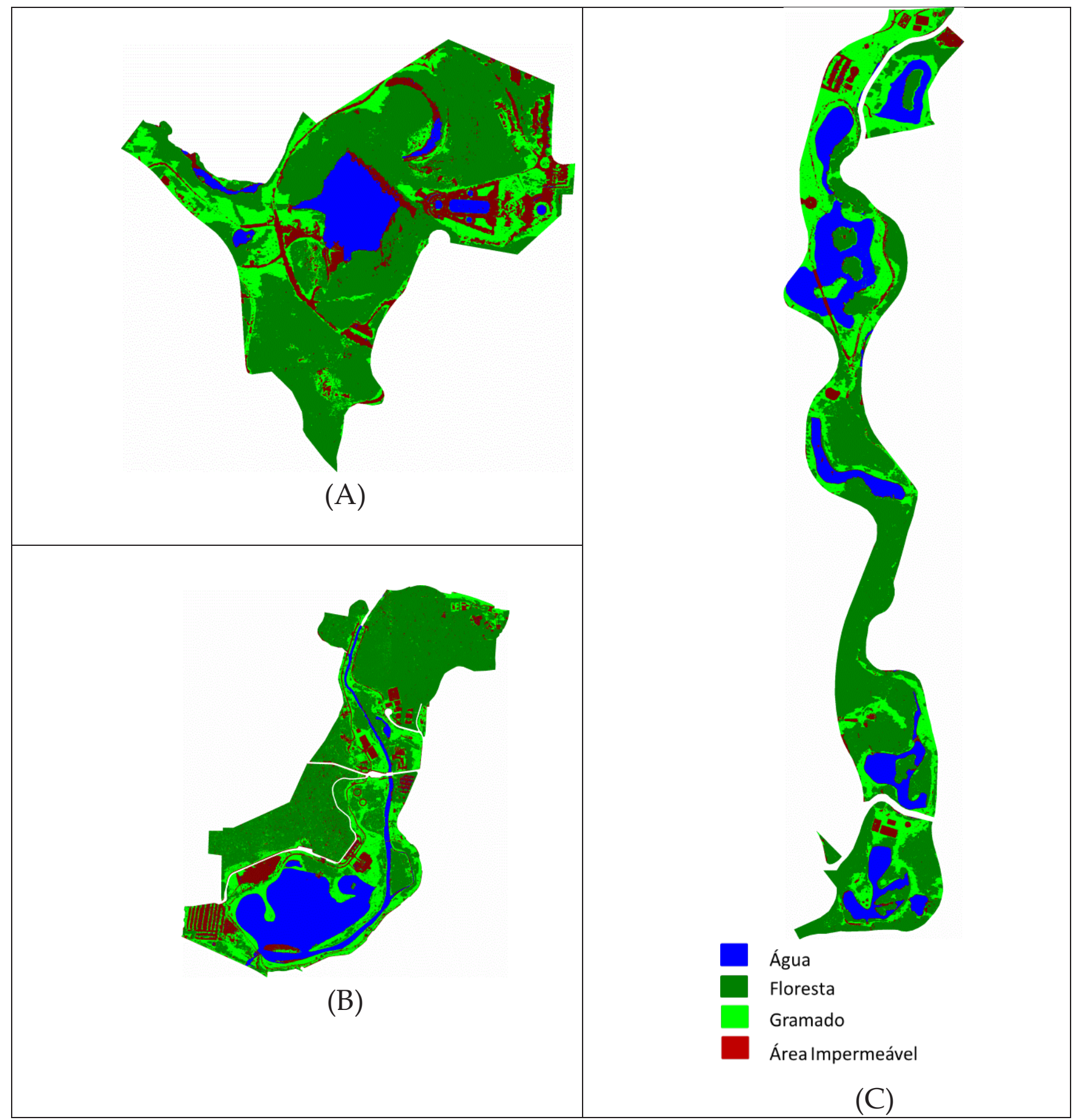

Figura 3. Áreas processadas no MultiSpec.: (A) parque Tanguá, (B) parque Barigui e (C) parque Tingui.

pessoal). Em 2009 foi registrada a morte de um animal adulto por atropelamento (Relato de funcionário da Prefeitura Municipal de Curitiba). Estes acontecimentos mostram que o elemento paisagístico "Área impermeável" desfavorece a ocupação de uma área pelas capivaras.

Apesar da frequência do elemento "Ârea impermeável" ter sido semelhante estatisticamente $(\chi 2=2,58)$ nas áreas amostradas, o parque Tanguá foi o que apresentou a maior frequência deste elemento paisagístico. Isso indica que entre as três áreas estudadas, o parque Tanguá é o que oferece maior pressão negativa aos animais.

Adicionado a isso, Tanguá é o parque que apresentou a menor frequência do elemento "Água" (9,1\%), sendo esta estatisticamente diferente da frequência do parque Tingui $(\chi 2=3,85)$. A área de vida das capivaras compreende um ambiente de água, um de floresta e uma área de campo. Cada porção do habitat é utilizada para uma atividade específica: os campos são utilizados para 
o forrageio; as áreas de mata servem para o repouso, abrigo e parição dos filhotes; e, os corpos d'água são utilizados para atividades reprodutivas, repouso e fuga de predadores (PEREIRA; ESTON, 2007; LEDRA et al., 2009). Entre os três elementos já citados a "Água" é o mais importante, sendo este determinante para a formação de grupos familiares e para o estabelecimento de uma população de capivaras, como já afirmado por Schaller e Crawshaw (1981), Moreira e Macdonald (1997) e Almeida (2012). Diante disso, mais uma vez, o parque Tanguá apresenta desvantagem com relação aos parques Tingui e Barigui.

No que se refere à presença e a quantidade dos elementos favoráveis a ocorrência de Hydrochoerus hydrochaeris, o parque Tingui está em vantagem diante dos parques Tanguá e Barigui por apresentar as maiores quantidades de "Água" (19,6\%) e de Gramado (27,4\%). A água, elemento mais importante, em maior abundância oferece aos animais maiores possibilidades de uso deste ambiente para a realização de suas necessidades e de seus comportamentos. Segundo Schaller e Crawshaw (1981), a capivara apresenta um comportamento reprodutivo variado de conquista da fêmea em período fértil, mas é dentro da água que a cópula acontece.

A abundância do gramado também confere vantagem ao parque Tingui, pois é no gramado (vegetação de cobertura) que se encontram as plantas mais consumidas pelas capivaras (QUINTANA et al., 1998; FOREROMONTANÃ et al., 2003; BORGES; COLARES, 2007).

Quanto ao parque Barigui, este não apresentou destaque favorável ou desfavorável à presença da espécie animal estudada, e foi à única área que não apresentou maiores ou menores frequências dos quatro elementos paisagísticos amostrados. No entanto, é o parque com a maior extensão em área total, aproximadamente 1.400 mil metros quadrado, contra $366 \mathrm{mil} \mathrm{m}^{2}$ do parque Tingui e 217 mil m² do parque Tanguá. Em relação à densidade populacional, este é o parque, entre os estudados, que suportaria a maior população de capivaras.

Em estudos anteriores (ALMEIDA; BIONDI, 2011; ALMEIDA, 2012; ALMEIDA et al., 2013), as capivaras foram visualizadas, sempre, ao redor dos lagos dos parques Tanguá, Tingui e Barigui. Ficar em vegetação ao redor de lagos ou rios é uma forma de defesa, pois a qualquer sinal de perigo as capivaras se lançam na água para se proteger (RODRIGUES, 2008). Ao observar o entorno dos lagos dos parques (Figura 3), pode-se verificar que ao redor do maior lago do parque Tanguá a predominância é de floresta, sendo essa bastante íngreme com inclinação de $90 \%$ nos pontos mais elevados (PMC, 2009). Contornando o lago do parque Barigui há uma preponderância do elemento "Gramado", cuja inclinação é de $5 \%$ acompanhando o fundo de vale. O mesmo pode ser verificado nos dois lagos localizados da região norte do parque Tingui, onde as capivaras foram observadas descansando e forrageando segundo Almeida e Biondi (2011), Almeida (2012) e Almeida et al. (2013).
Tanto o parque Tanguá quanto o parque Tingui e parque Barigui apresentaram maiores proporções do elemento "Floresta" (58,3\%; 46,6\% e 51,4\% respectivamente), do que Gramado, Água ou Área impermeável. Isso reforça a importância destas áreas verdes com remanescentes de floresta para a cidade de Curitiba. De acordo com Franchin et al. (2004) as cidades contêm fragmentos de hábitat natural e podem ser manejadas e desenhadas para otimizar a abundância de vida silvestre. Assim, estes fragmentos podem funcionar como refúgio para espécies animais e promover oportunidade para evitar a extinção local de várias espécies.

Os parques de Curitiba que apresentam características de habitat para as capivaras são áreas imprescindíveis para a garantia da conservação desta espécie nativa, pois segundo Ledra et al. (2009) a área de vida desta espécie animal além de conter todos os tipos de habitat e recursos necessários, é estável quanto à sua localização e configuração.

\section{Conclusão}

O uso do Sensoriamento Remoto foi peça chave para o estudo do habitat de capivara em parques de Curitiba, PR. Uma das vantagens desta ferramenta é a viabilização de resultados em curto espaço de tempo. Por meio dele, foi possível verificar as semelhanças e as diferenças entre as paisagens dos parques Tanguá, Tingui e Barigui, onde há a ocorrência desta espécie. Estudos como estes são fundamentais para o entendimento das populações animais que vêm ocupando ou que já ocupam os centros urbanos. A compreensão destes novos ambientes, que se tornam opções de habitat, é imprescindível para a conservação da fauna tanto silvestre quanto urbana.

\section{Referências}

ABE, L.A.; BARDDAL, M.L.; BERNARDI, D. Mapeamento e caracterização da cobertura vegetal do Parque Barigüi, Curitiba, Paraná. In: 40 Anos de Engenharia Florestal - Universidade Federal do Paraná. Pesquisa Florestal Online, Curitiba, 2000. Anais...Curitiba: UFPR/Comitê de Pesquisa do Setor de Ciências Agrárias, 2000.

ALHO, C.J.R.; CAMPOS,Z.M.S.; GONÇALVES,H.C. Ecologia de capivara (Hydrochaeris hydrocharis, Rodentia) do Pantanal: habitats, densidade e tamanho de grupo. Revista Brasileira de Biologia, v. 47 , n. 1/2, p. 99-110, 1987.

ALMEIDA, A.M.R.; BIONDI, D. A study of the landscape and the occurrence of Hydrochaerus hydrochaeris at Tingui Municipal Park in Curitiba, State of Parana. Revista de Ciências Agrárias, v. 54, 
n. 3, p. 280-289, 2011.

ALMEIDA, A.M.R.; SILVA JUNIOR, A; LEITE, F.C.; MACEDO, L.F.F.; PEREIRA, S.C. Relatório mastofauna: diagnóstico do Aterro Sanitário da Caximba, Curitiba-PR. Prefeitura Municipal de Curitiba. 2011.

ALMEIDA, A.M.R. A paisagem do Parque Tingui - Curitiba, PR - e a presença de capivara (Hydrochoerus hydrochaeris, Linnaeus, 1766). $92 \mathrm{f}$. Dissertação de Mestrado, Universidade Federal do Paraná, Curitiba. 2012.

ALMEIDA, A.M.R.; ÁRZUA, M.; TRINDADE, P.W.S.; SILVA JUNIOR, A. Capivaras (Hydrochoerus hydrochaeris, Linnaeus, 1766) (Mammalia: Rodentia) em áreas verdes do município de Curitiba (PR). Estudos de Biologia, v. 35, n. 84, p. 9-16, 2013.

BAGATINI, T. Evolução dos índices de atropelamento de vertebrados silvestres nas rodovias do entorno da Estação Ecológica Água Emendadas, DF, Brasil, e eficácia de medidas mitigadoras. 74 f. Dissertação (Mestrado em Ecologia) - Instituto de Ciências Biológicas, Universidade de Brasília. 2006.

BARROS, K.S.; TOKUMARU, R.S.; PEDROZA, J.P.; NOGUEIRA, S.C. Vocal repertoire of captive capybara (Hydrochoerus hydrochaeris): structure, context and function. Ethology, v. 117, p. 83-93, 2011.

BIONDI, D.; ALTHAUS, M. Árvores de rua de Curitiba: cultivo e manejo. Curitiba: FUPEF, 2005.

BORGES, L. V.; COLARES, I. G. Feeding habits of capybaras (Hydrochoerus hydrochaeris, Linnaeus 1766), in the Ecological Reserve of Taim (ESEC - Taim) - South of Brazil. Brazilian Archives of Biology and Technology, v. 50, n. 3, p. 409 - 416, 2007.

BRESSAN, P.M.; KIERULFF, C.M.; SUGIEDA, A.M. Fauna ameaçada de extinção no estado de São Paulo: vertebrados. São Paulo: Secretaria do Meio Ambiente, 2009.

CREED, J.C. Capybara (Hydrochaeris hydrochaeris Rodentia: Hydrochaeridae) a mammalian seagrass herbivore. Estuaries, v. 27, n. 2, p. 197-200, 2004.

DANTAS, C.I.; SOUZA, C.M.C. Arborização urbana na cidade de Campina Grande - PB: Inventário e suas espécies. Revista de Biologia e Ciências da Terra, v. 4, n. 2, 2004, n/p. Disponível em
$<$ http://eduep.uepb.edu.br/rbct/ sumarios/pdf/ arborizaurbana.pdf $>$ Acesso em: 24 set 2013.

FERNANDEZ, F. O poema imperfeito, crônicas de biologia, conservação da natureza e seus heróis. Curitiba: UFPR, 2004.

FERRAZ, K.P.M.B.; SANTOS-FILHO, R.M.F.; PIFFER, T.R.O.; VERDADE, L.M. Biologia e manejo da capivara: do controle de danos ao máximo rendimento sustentável. In: A Produção Animal na Visão dos Brasileiros, Piracicaba: FEALQ, 2001, v. 1, p. $580-588$.

FERRAZ, K.M.P.M.B.; LECHEVALIER, M.; COUTO, H.T.Z.; VERDADE, L.M. Damage caused by capybaras in a corn field. Scientia Agricola, v. 60, n. 1, p. 191-194, 2003.

FERRAZ, K.M.P.M.B.; FERRAZ, S.F.B.; MOREIRA, J.R.; COUTO, H.T.Z.; VERDADE, L.M. Capybara (Hydrochoerus hydrochaeris) distribution in agroecosystems: a crossscale habitat analysis. Journal of Biogeography, v. 34, p. 223-230, 2007.

FERRAZ, K.M.P.M.B.; PETERSON, A.T.; SCACHETTI-PEREIRA; VETTORAZZI, C.A.; VERDADE,L.M. Distribution of capybara in an agroecosystem Brazil, based on ecological niche modeling. Journal of Mammalogy, v. 90, n. 1, p. 189-194, 2009.

FIRKOSKI, C. O hábitat para a fauna: manipulação em micro escala. Floresta, v. 21, n. 1, p. 27-43, 1991.

FRANCHIN, A.G.; OLIVEIRA, G.M.; MELO, C.; TOMÉ, E.R.; MARÇAL JUNIOR, O. Avifauna do campus Umuarama Universidade Federal de Uberlândia (Uberlândia, MG). Revista Brasileira de Zoociências, Juiz de Fora, v. 6, n. 2, p. 219-230, 2004.

FORERO-MONTAÑA, J.; BETANCUR, J.; CAVELIER, J. Dieta del capibara Hydrochaeris hydrochaeris (Rodentia: Hydrochaeridae) en Caño Limón, Arauca, Colômbia. Revista Biologia Tropical, v. 51, n. 2, p. 579-590, 2003.

GARCIA, L.S.; SANTOS, A.M.; FOTOPOULOS, I.G.; FURTADO, R.S. Fragmentação florestal e sua influência sob a fauna: estudo de caso na província ocidental da Amazônia, município de Urupá, estado de Rondônia. In: SIMPÓSIO BRASILEIRO DE SENSORIAMENTO REMOTO, 16, 2013, Foz do Iguaçu. Anais...Foz do Iguaçu, 2013.

HERRERA, E.A.; MACDONALD, D.W. Group stability and structure of a capybara population. 
Symposia of the Zoological Society of London, $\mathrm{n}$. 58, p. 115-130, 1987.

HOBBS, R.J.; HUENNEKE, L. F. Disturbance, diversity and invasion: implications for conservation. Conservation Biology, v. 6, n. 3, p. 324-337, 1992.

IPPUC - Instituto de Pesquisa e Planejamento Urbano de Curitiba. 2010. Curitiba em dados. Disponível em: <http://ippucweb.ippuc.org.br/Bancodedados/ Curitibaemdados/Curitiba_em_dados_Pesquisa. htm> Acesso em: 25 set 2013.

IPPUC - Instituto de Pesquisa e Planejamento Urbano de Curitiba. Hidrografia. Disponível em $<$ http://ppucweb.ippuc.org.br/Bancodedados/ Curitibaemdados/Curitiba_em_dados_Pesquisa. $\mathrm{htm}>$ Acesso em 18 set 2013.

LANDIS, J.R.; KOCH, G.G. The measurement of observer agreement for categorical data. Biometrics, v. 33, n. 1, p. 159-174, 1977.

LANG, S.; BLASCHKE, T. Análise da paisagem com SIG. São Paulo: Oficina de Textos, 2009.

LEDRA, C.K. LEDRA, L.C. MADRUGA, D.A.; THIVES, A.; SIEBERT, U.O.; THISEN, J.R. Ecologia da capivara (Hydrochaeris hydrochaeris) no perímetro urbano de Rio do Sul, SC: população, alimentação e comportamento. Revista Caminhos, v. 1, n. 10, p. 204-217, 2009.

MANTOVANI, J.E. Estudo e monitoramento de animais através do sensoriamento remoto e do geoprocessamento. In: SIMPÓSIO DE GEOTECNOLOGIAS NO PANTANAL, 1, 2006, Campo Grande. Anais... Campo Grande, 2006.

MARGARIDO, T.C.C.; BRAGA, F.G. Mamíferos. In: MIKICH, S.B.; BÉRNILS, R.S. Livro Vermelho da Fauna Ameaçada no Estado do Paraná. Curitiba: Instituto Ambiental do Paraná. 2004.

MASCARENHAS, L.M.A.; FERREIRA, M.E.; FERREIRA, L.G. Sensoriamento remoto como instrumento de controle e proteção ambiental: análise da cobertura vegetal remanescente na bacia do rio Araguaia. Sociedade \& Natureza, v. 21, n. 1, p. 5-18, 2009.

MIRETZKI, M. Inventário de quirópteros de Curitiba (Paraná, Brasil). In: CONGRESSO BRASILEIRO DE ZOOLOGIA, 11, 1996, Porto Alegre. Anais...Porto Alegre, 1996.
MMA - Ministério do Meio Ambiente. O corredor central da Mata Atlântica: uma nova escala de conservação da biodiversidade. Brasília: Ministério do Meio Ambiente, 2006.

MOREIRA, J.R.; MACDONALD, D.W. Técnicas de manejo de capivaras e outros grandes roedores na Amazônia. In: VALLADARES-PADUA, C.; BODMER, R.E; CULLER, L. Manejo e conservação da vida Silvestre no Brasil. Brasília: Sociedade Civil Mamirauá, 1997, p. 186-213.

OLIVEIRA, J.A.; BONVICINO, G.R. Ordem Rodentia. In: REIS, N. R.; PERACCHI, A. L.; PEDRO, W. A.; LIMA, I. P. Mamíferos do Brasil. $2^{\underline{a}}$ edição, Londrina: Nélio R. dos Reis, 2011. p. 358-433.

PARQUES E PRAÇAS DE CURITIBA. Lei n ${ }^{\circ} 9.804$ de 03 de janeiro de 2000. Disponível em: <http:// www.curitiba.pr.gov.br/multimidia/00086311.pdf> Acesso em: 16 set 2013.

PEREIRA,H.F.A.; ESTON,M.R. Biologia e manejo de capivaras (Hydrochoerus hydrochaeris) no parque estadual Alberto Löfgren, São Paulo, Brasil. Revista do Instituto Florestal, v. 19, n. 1, p. 55-64, 2007.

PMC - Prefeitura Municipal de Curitiba. Plano de manejo do Parque Municipal do Tanguá. Curitiba. 2002.

PMC - Prefeitura Municipal de Curitiba. Plano de manejo do Parque Natural Municipal Barigui. Curitiba. 2007.

PMC - Prefeitura Municipal de Curitiba. Plano de manejo do Parque Tingui. Curitiba, 2009.

PORTO, M.L; MENEGAT, R. Ecologia de paisagem: um novo enfoque na gestão dos sistemas da terra e do homem. In: MENEGAT, R.; ALMEIDA, G. Desenvolvimento sustentável e gestão ambiental nas cidades: estratégia a partir de Porto Alegre. Porto Alegre: UFRGS, 2004, p. 361-375.

QUINTANA, R.D.; MONGE, S.; MALVÁREZ, A.I. Conposición y diversidad de las dietas del capibara (Hydrochaeris hydrochaeris) y del ganho doméstico em um agroecossistema de la región central de entre ríos, Argentina. Ecotropicos, v. 11, n. 1, p. 33-44, 1998.

RISSER, P. G. Landscape ecology: state-of-the-art. In: TURNER, M. G. Landscape heterogeneity and disturbance. New York: Springer-Verlag, 1987, p. 3-14. 
RODRIGUES, C.A.G.; BEZERRA, B.C.; ISHII, I.H.; CARDOSO, E.L.; SORIANO, B.M.A.; OLIVEIRA, H. Arborização urbana e produção de mudas de essências florestais nativas em Corumbá, MS. Corumbá: Embrapa Pantanal, 2002.

RODRIGUES, M.V. Comportamento social e reprodutivo de capivaras Hydrochoerus hydrochaeris Linnaeus, 1766 (Rodentia) em áreas com diferentes níveis de influência urbana. $46 \mathrm{f}$. Dissertação (Mestrado em Medicina Veterinária), Universidade Federal de Viçosa, Minas Gerais, 2008.

ROPPA, C.; FALKENBERG, J.R.; STANGERLIN, D.M.; BRUN, F.G.K.; BRUN E.J.; LONGHI, S.J. Diagnóstico da percepção dos moradores sobre a arborização urbana na vila estação colônia, bairro Camobi, Santa Maria-RS. Revista da Sociedade Brasileira de Arborização Urbana, v. 2, n. 2, p. 1130, 2007.

SCHALLER, G.S.; CRAWSHAW, P.G. Social organization in a capybara population. Saugetierkundliche Mitteilungen, v. 29, p. 3-16, 1981.

SILVEIRA, L. Ecologia e conservação dos mamíferos carnívoros do Parque Nacional das Emas, Goiás. 125 f. Dissertação (Mestre em Biologia), Universidade Federal de Goiás, Goiânia, 1999.

SPIRN, A.W. O jardim de granito. Tradução de Paulo Renato Mesquita Pellegrino. São Paulo: Edusp, 1995.

STRAUBE, F.C.; CARRANO, E.; SANTOS, R.E.F.; SCHERRE-NETO, P.; RIBAS, C.F., MEIJER, A.A.R.; VALLEJOS, M.A.V.; LANZER, M.; KKLEMANNJÚNIOR, L.; AURÉLIO-SILVA, M.; URBEN-FILHO, A.; ARZUA, M.; LIMA, A.M.X.; SOBÂNIA, R.L.M.; DECONTO, L.R.; BISPO, A.A.; JESUS, S.; ABILHÔA, V. Aves de Curitiba: coletânea de registros. Curitiba: Prefeitura Municipal de Curitiba, 2009.

VARGAS, F.C; VARGAS, S.C.; MORO, M.E.G.; SILVA, V.; CARRER, C.R.O. Monitoramento populacional de capivaras (Hydrochaeris hydrochaeris Linnaeus, 1766) em Pirassununga, SP, Brasil. Ciência Rural, v. 37, n. 4, p. 1104-1108, 2007.

VERDADE, L.M. \& FERRAZ, K.M.P.M.B. Capybaras (Hydrochoerus hydrochaeris) on an anthropogenic habitat in southeastern Brazil. Brazilian Journal of Biology, v. 66, n. 1b, p. 371-378, 2006. 